\title{
Host specificity of the ruminal bacterial community in the dairy cow following near-total exchange of ruminal contents ${ }^{1}$
}

\author{
P. J. Weimer, ${ }^{\star} \dagger^{2}$ D. M. Stevenson, ${ }^{*}$ H. C. Mantovani, $\neq$ and S. L. C. Man $†$ \\ *USDA-ARS, US Dairy Forage Research Center, Madison, WI 53706 \\ †Department of Bacteriology, University of Wisconsin-Madison, Madison 53706 \\ ‡Departamento de Microbiologia, Universidade Federal de Viçosa, Viçosa-MG, 36571-000, Brazil
}

\begin{abstract}
The purpose of this study was to examine the stability and host specificity of a cow's ruminal bacterial community following massive challenge with ruminal microflora from another cow. In each of 2 experiments, 1 pair of cows was selected on the basis of differences in ruminal bacterial community composition (BCC), determined by automated ribosomal intergenic spacer analysis (ARISA), a culture-independent "community fingerprinting" technique. Each pair of cows was then subjected to a 1-time exchange of $>95 \%$ of ruminal contents without changing the composition of a corn silage/ alfalfa haylage-based TMR. In experiment 1, the 2 cows differed $(P<0.01)$ in prefeed ruminal $\mathrm{pH}($ mean $=6.88$ vs. 6.14) and prefeed total VFA concentration (mean $=$ 57 vs. $77 \mathrm{mM}$ ), averaged over $3 \mathrm{~d}$. Following exchange of ruminal contents, ruminal $\mathrm{pH}$ and total VFA concentration in both cows returned to their preexchange values within $24 \mathrm{~h}$. Ruminal BCC also returned to near its original profile, but this change required $14 \mathrm{~d}$ for 1 cow and $61 \mathrm{~d}$ for the other cow. In experiment 2, the 2 other cows differed in prefeed ruminal $\mathrm{pH}$ ( mean $=6.69$ vs. 6.20) and total VFA concentration (mean $=101$ vs. $136 \mathrm{mM}$ ). Following exchange of ruminal contents, the first cow returned to its preexchange $\mathrm{pH}$ and VFA values within $24 \mathrm{~h}$; the second cow's rumen rapidly stabilized to a higher prefeed $\mathrm{pH}($ mean $=6.47)$ and lower prefeed VFA concentration (mean $=120 \mathrm{mM}$ ) that was retained over the $62-\mathrm{d}$ test period. Both cows reached somewhat different $\mathrm{BCC}$ than before the exchange. However, the $\mathrm{BCC}$ of both cows remained distinct and were ultimately more similar to that of the preexchange $\mathrm{BCC}$ than of the donor animal BCC. The data indicate that the host animal can quickly reestablish its characteristic ruminal $\mathrm{pH}$ and VFA concentration despite
\end{abstract}

\footnotetext{
Received June 2, 2010.

Accepted August 26, 2010.

${ }^{1}$ Mention of specific products is for informational purposes only and does not imply a warranty or endorsement over other products not mentioned.

${ }^{2}$ Corresponding author: paul.weimer@ars.usda.gov
}

dramatic perturbation of its ruminal microbial community. The data also suggest that ruminal BCC displays substantial host specificity that can reestablish itself with varying success when challenged with a microbial community optimally adapted to ruminal conditions of a different host animal.

Key words: bacterial community, rumen, rumen $\mathrm{pH}$, volatile fatty acid

\section{INTRODUCTION}

The microbial community of the rumen is responsible for converting ingested feed into the VFA that serve as the major energy source for the ruminant host, and for providing a substantial portion of the host's protein requirements (Hungate, 1966). Ruminal bacteria are the most numerous of the microbial inhabitants (Russell, 2002), and until recently, the number of different bacterial species in the rumen was vastly underestimated (Krause and Russell, 1996; Stevenson and Weimer, 2007), largely because most bacterial species have resisted the laboratory cultivation that ordinarily precedes species identification and characterization.

Culture-independent community fingerprinting techniques such as automated ribosomal intergenic spacer analysis (ARISA) have greatly expanded our understanding of the diversity of the ruminal bacterial population and have indicated that the bacterial community composition (BCC) of dairy cattle can differ substantially, even among animals fed the same diet and with similar milk yields and compositions (Weimer et al., 2010; Welkie et al., 2010). This raises the possibility that ruminal BCC may be optimally adapted to its particular ruminant host, and can display substantial resistance to colonization by bacterial strains not adapted to the recipient host. Host specificity would explain in part the inconsistent effects of targeted additions of pure bacterial strains to the rumen. Such additions have produced mixed results (compare Jones and Megarrity, 1986 and Gregg et al., 1998 with Varel et al., 1995 and Krause et al., 1999) that appear to depend largely on whether the added strain can fill an empty niche in the microbial community (Weimer, 1998). On 
the basis of these reports, we hypothesized that the ruminal BCC displays sufficient host specificity to resist establishment of allochthonous (non-native) bacterial strains, even when the latter are inoculated in very large dosages.

One approach to examine the specificity between the host animal and its ruminal microflora is to crossinoculate ruminal contents between cows. Several such cross-inoculations have been reported in the literature (Satter and Bringe, 1969; Cole, 1991), but these studies have focused on animal responses (particularly feed intake and the profiles of $\mathrm{pH}$ and VFA), without examination of the effects on population distributions of the many members of the microbial community. We report here that near-complete exchange of ruminal contents between pairs of cows generally results in a reassembly of the bacterial communities over a period of approximately 2 to $9 \mathrm{wk}$, to resemble, to varying degrees, those before the exchange. In addition, the exchange is accompanied by a surprisingly rapid return to the preexchange $\mathrm{pH}$ and VFA profiles, suggestive of a major influence of the cow on its own ruminal chemistry.

\section{MATERIALS AND METHODS}

Two ruminal exchange experiments were conducted with lactating, ruminally fistulated Holstein cows according to a protocol approved by the University of Wisconsin-Madison Research Animal Resource Center. Cows were maintained in tiestalls, fed once daily, milked twice daily, and had continuous access to water. The first experiment comprised 2 cows whose ruminal BCC (determined by ARISA and correspondence analysis; see below) was shown to be the most different among 5 cows tested. This experiment was conducted November 17,2008 , to January 23, 2009, at the University of Wisconsin Dairy Cattle Instructional Center in Madison. The cows were fed a TMR that contained (DM basis) $35.1 \%$ corn silage, $23.1 \%$ alfalfa haylage, $13.4 \%$ coarse-ground corn, $10 \%$ distillers dried grains, $6.4 \%$ soybean meal, $3.2 \%$ corn gluten feed, $0.69 \% \mathrm{CaCO}_{3}$, $0.63 \%$ soy hulls, $0.4 \% \mathrm{NaHCO}_{3}, 0.23 \%$ iodized $\mathrm{NaCl}$, $0.12 \% \mathrm{CaHPO}_{4}, 0.11 \%$ DynaMate, $0.09 \% \mathrm{MgO}$, and supplemental vitamins and trace minerals. The second experiment comprised 2 cows whose BCC was shown to be the most different among 18 cows tested. This test was conducted May 18 to July 21, 2009, at the US Dairy Forage Research Center farm near Prairie du Sac, WI. These cows were fed once daily with a TMR that contained (DM basis) $29.6 \%$ corn silage, $27.9 \%$ alfalfa haylage, $25.5 \%$ corn grain, $7.4 \%$ roasted soybeans, $2.6 \%$ vitamin and mineral mix, $1.9 \%$ whole cottonseed, $1.8 \%$ dried distillers grains, $1.8 \%$ soybean meal, and $1.5 \%$ blood meal, along with Rumensin 80 (Elanco Animal Health, Greenfield, IN) to provide monensin at $13 \mathrm{mg} /$ $\mathrm{kg}$ of diet DM.

Ruminal sampling was conducted just before feeding on 2 successive days $(-2$ and -1$)$ before the exchange of ruminal contents. On the day of the exchange, ruminal contents were sampled just before (PRE) and just after (POST) exchanging ruminal contents, and subsequently just before feeding on various days as indicated in the Results section. Samples were placed on ice and transported back to the laboratory, and then archived at $-80^{\circ} \mathrm{C}$ for analysis at the conclusion of each experiment.

The exchanges themselves were accomplished by hand-emptying the rumens, first by withdrawing hand samples of wet solids, and eventually by removal of residual ruminal liquor using a 0.25 -L plastic cup. During emptying, the experimenters wore shoulder-length polyethylene gloves (Nasco, Ft. Atkinson, WI), and care was taken to open folds in the rumen wall to access additional contents. Although direct measurements were not employed, we estimate that we removed approximately $95 \%$ of the ruminal contents from each cow. The removed solids and liquids were placed in precleaned large plastic garbage cans. Upon conclusion of the ruminal emptying, the wet solid ruminal contents from the donor cows were hand-stuffed into the rumen of the recipient cow, and the residual liquor was then poured into the rumen. For both experiments, the exchanges were completed within approximately $30 \mathrm{~min}$.

Ruminal $\mathrm{pH}$ and temperature were measured at each ruminal sampling using a model 340i datalogging $\mathrm{pH}$ meter fitted with a SenTix 41 electrode (WTW, Weinheim, Germany). The $\mathrm{pH}$ measurement system was calibrated at $\mathrm{pH} 7.00$ and 4.00 immediately before use. Fermentation acids (VFA and lactate) were determined by HPLC, as described previously (Weimer et al., 1991). Comparisons of BCC were performed using ARISA, a culture-independent community fingerprinting technique that examines the relative abundance of the internally transcribed sequence between the $16 \mathrm{~S}$ and $23 \mathrm{~S}$ rRNA genes present in all bacteria. The methods for DNA isolation, PCR amplification of the internal transcribed spacer sequence, separation of amplicons by ARISA, and correspondence analysis of the amplicon profiles obtained by capillary electrophoresis, have been described (Weimer et al., 2010). Amplicon profiles were compared using an analysis of similarity (ANOSIM). The ANOSIM R-value was calculated from a BrayCurtis distance table (Ludwig and Reynolds, 1988) according to the method of Clarke (1993). Calculations were performed using custom software written in the C programming language. 
a)

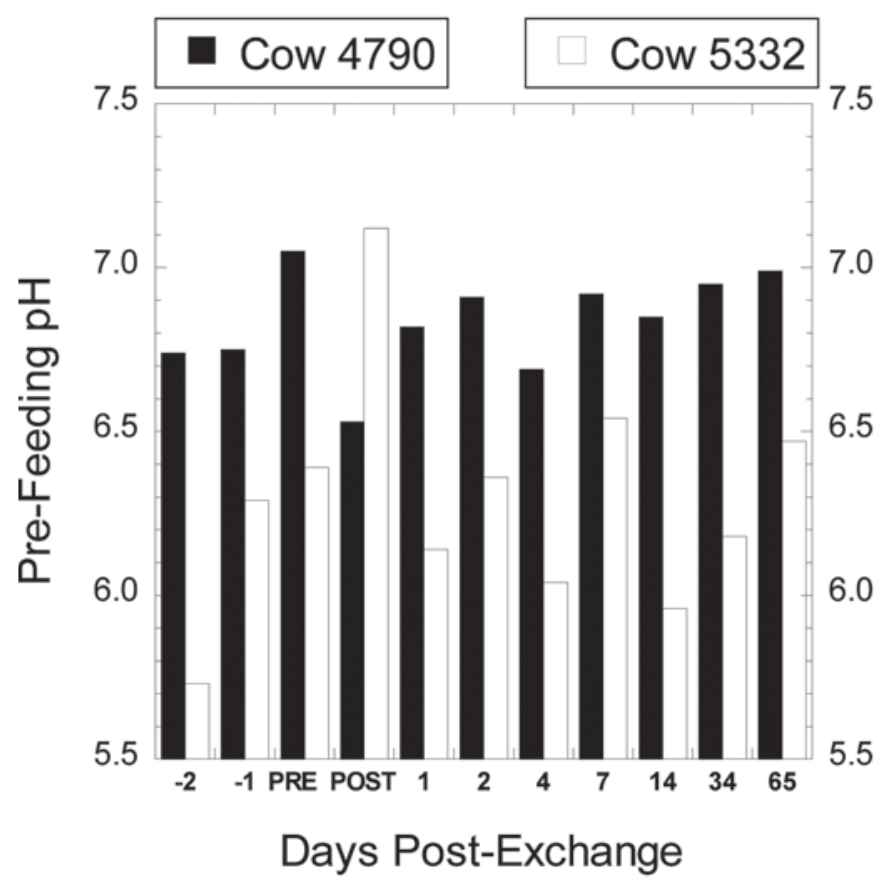

b)

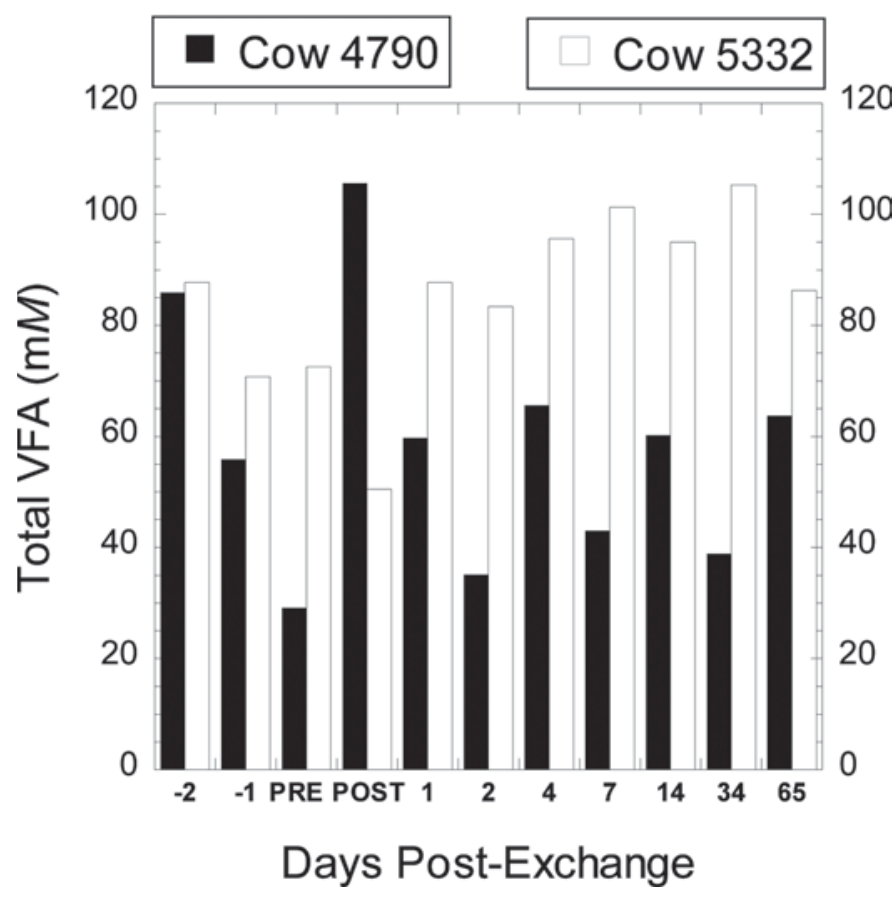

Figure 1. Prefeed $\mathrm{pH}$ and prefeed total VFA concentrations in the rumina of 2 cows in experiment 1 . PRE $=$ sample collected immediately before exchange. POST = sample immediately after exchange. All other samples were collected immediately before feeding on the indicated number of days before the exchange (negative value) or after the exchange (positive value). Samples were collected individually but analyzed in duplicate.

\section{RESULTS}

\section{Animal Health and Behavior}

For both experiments, exchange of ruminal contents had no visible effects on the cows or their eating behavior, and no animal health issues were encountered during the ensuing 9 wk of the experiment.

Experiment 1. In experiment 1, as shown in Figure $1 \mathrm{~A}$, cows differed significantly $(P<0.05)$ in prefeed $\mathrm{pH}$ prior to exchange of ruminal contents (cow 4790, $\mathrm{pH}$ 6.85; cow 5332, $\mathrm{pH}$ 6.14). These differences were almost reversed upon exchange (cf. PRE vs. POST in Figure 1), but were quickly reestablished, by the end of the first day, after the exchange. The mean prefeed $\mathrm{pH}$ values for all time points after the switch (cow 4790, $\mathrm{pH}$ 6.88 , cow 5332, $\mathrm{pH} 6.24$ ) were remarkably similar to the mean values measured before the exchange.

The 2 cows also differed significantly in prefeed total VFA concentration prior to exchange of ruminal contents (cow 4790, $57 \mathrm{mM}$; cow 5332, $77 \mathrm{mM}$; Figure 1B). As in the case of $\mathrm{pH}$, the total VFA concentrations displayed a reversal immediately following the switch (cf. PRE vs. POST in Figure 1B), but then quickly returned to the previous pattern. The mean total VFA concentration of cow 4790 for all points after the exchange $(52 \mathrm{mM})$ was similar to the preexchange mean. For cow 5332, the postexchange mean $(93 \mathrm{mM})$ was somewhat higher than the preexchange mean, but this difference was not significant $(P>0.05)$.

Figure 2 shows the changes in $\mathrm{BCC}$ during the course of the experiment. As expected from the high dimensionality of the data (178 different amplicon lengths, AL, detected across the data set), the 2 axes on the ordination biplot accounted for only approximately $15 \%$ of the variation in the data. For both cows, BCC immediately following the exchange showed strong similarity to those of the donor inoculum immediately before the exchange (i.e., 4790 POST resembled 5332 PRE, and 5332 POST resembled 4790 PRE), as would be expected from an almost complete exchange. For both cows, $\mathrm{BCC}$ following the exchange resulted in substantial changes in BCC, especially during the first week. However, for both cows, the BCC eventually became very similar to that observed just before the exchange.

To examine more closely the similarities in BCC across the full data set, the ARISA data were examined by ANOSIM, a method that involves ranking of the data from discrete sets of sample groups to each other. This provides a more complete comparison of groups of communities, because it incorporates the full data set rather than only the 2 correspondence axes 


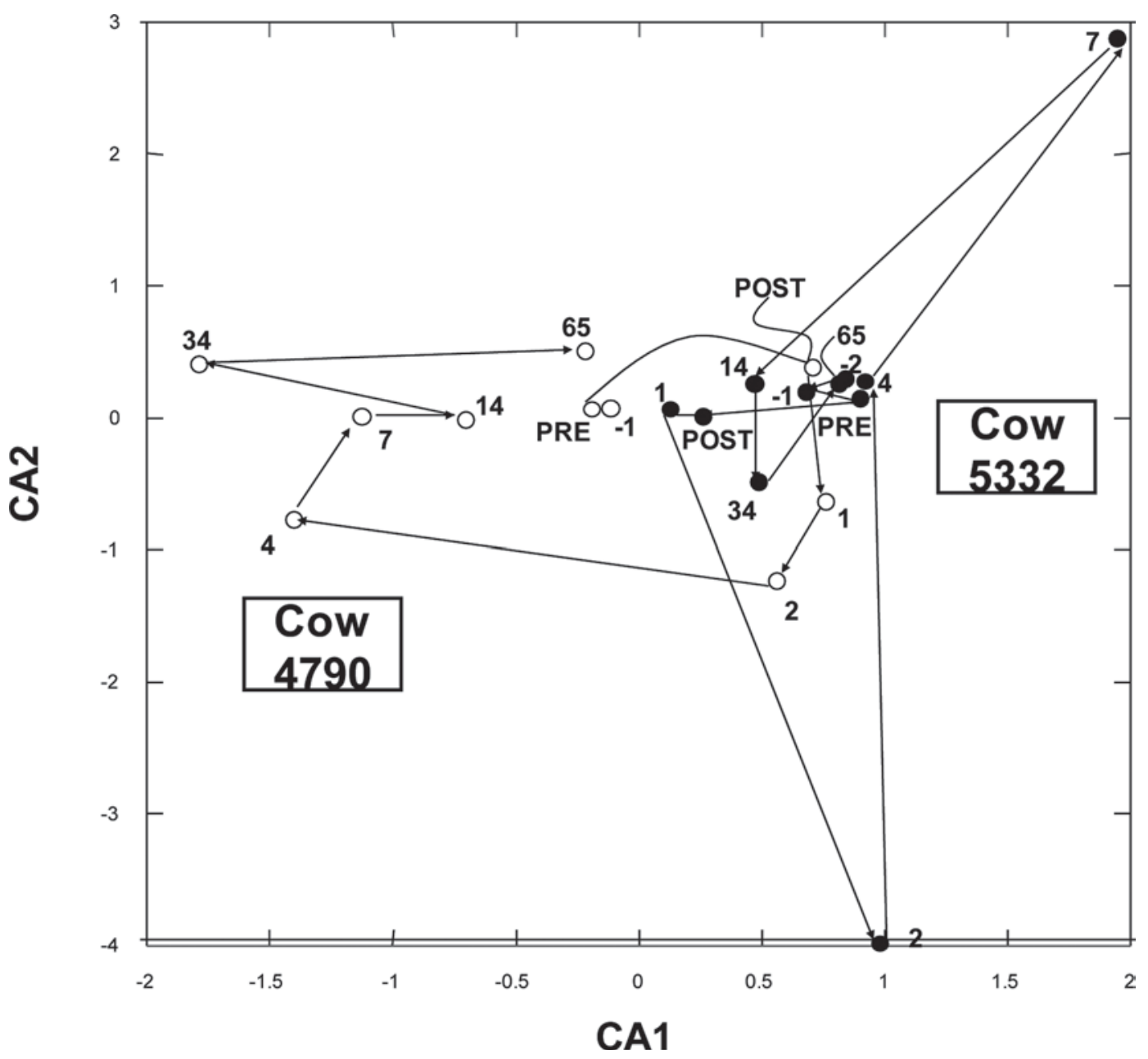

Figure 2. Ordination biplots of bacterial community composition $(\mathrm{BCC})$ for experiment 1 (cow $4790=\circ$; cow $5332=\bullet$ ). Coordinates were obtained from correspondence analysis of peak areas in capillary electropherograms of samples resulting from automated ribosomal intergenic spacer analysis (ARISA) of amplified internal transcribed spacer segments of microbial DNA, using domain bacteria-specific primers. The CA1 and CA2 represent the first and second correspondence axes, respectively. Each data point represents a single sample at the indicated time (in days) relative to the day of the ruminal contents exchange. PRE $=$ sample collected immediately before exchange. POST $=$ sample immediately after exchange. Samples with similar BCC are located more closely together, and distance between points increases as BCC becomes less similar.

that account for the largest variation in the data. The ANOSIM R-values can range from -1 (no differences between groups) to +1 (maximum differences between groups) and are presented in Figure 3 for comparison of specific combinations of cow and sampling time. Cows 4790 and 5332 displayed substantial differences before exchange of ruminal contents $(\mathrm{R}=0.450$, comparison A in Figure 3) and, for each cow, BCC differed from the original $\mathrm{BCC}$ over the few days following the exchange (comparisons $\mathrm{B}$ and $\mathrm{C}$ ), as to be expected for the exchange procedure. Comparison of BCC for the complete set of data points from the cow before the exchange with those in the same cow after the exchange yielded highly negative $\mathrm{R}$-values for both cow $4790(\mathrm{R}=-0.815$, comparison $\mathrm{I})$ and cow $5332(\mathrm{R}=$ -0.772 , comparison L). Comparisons of BCC before the exchange with those at the last 2 time points $(34 \mathrm{~d}$ and $65 \mathrm{~d}$ ) after the exchange gave higher R-values ( $\mathrm{R}$ $=-0.500$ for cow 4790, comparison $\mathrm{J} ; \mathrm{R}=0.200$ for cow 5332, comparison K), suggesting that some differences existed even at these longer postexchange times, but these higher R-values may have been due to the small number of samples under comparison. The overall trend to return toward the original $\mathrm{BCC}$ of the recipient cow at the later time points was further indicated by the much lower $\mathrm{R}$-values from comparisons of the recipient cow at later time points with the same cow before the exchange, relative to that from the donor cow before the exchange (comparison J vs. F for cow 4790, comparison $\mathrm{K}$ vs. $\mathrm{G}$ for cow 5332). The R-value from the comparison between the 2 cows at the later time points following the exchange (comparison $\mathrm{H}$ ) sug- 


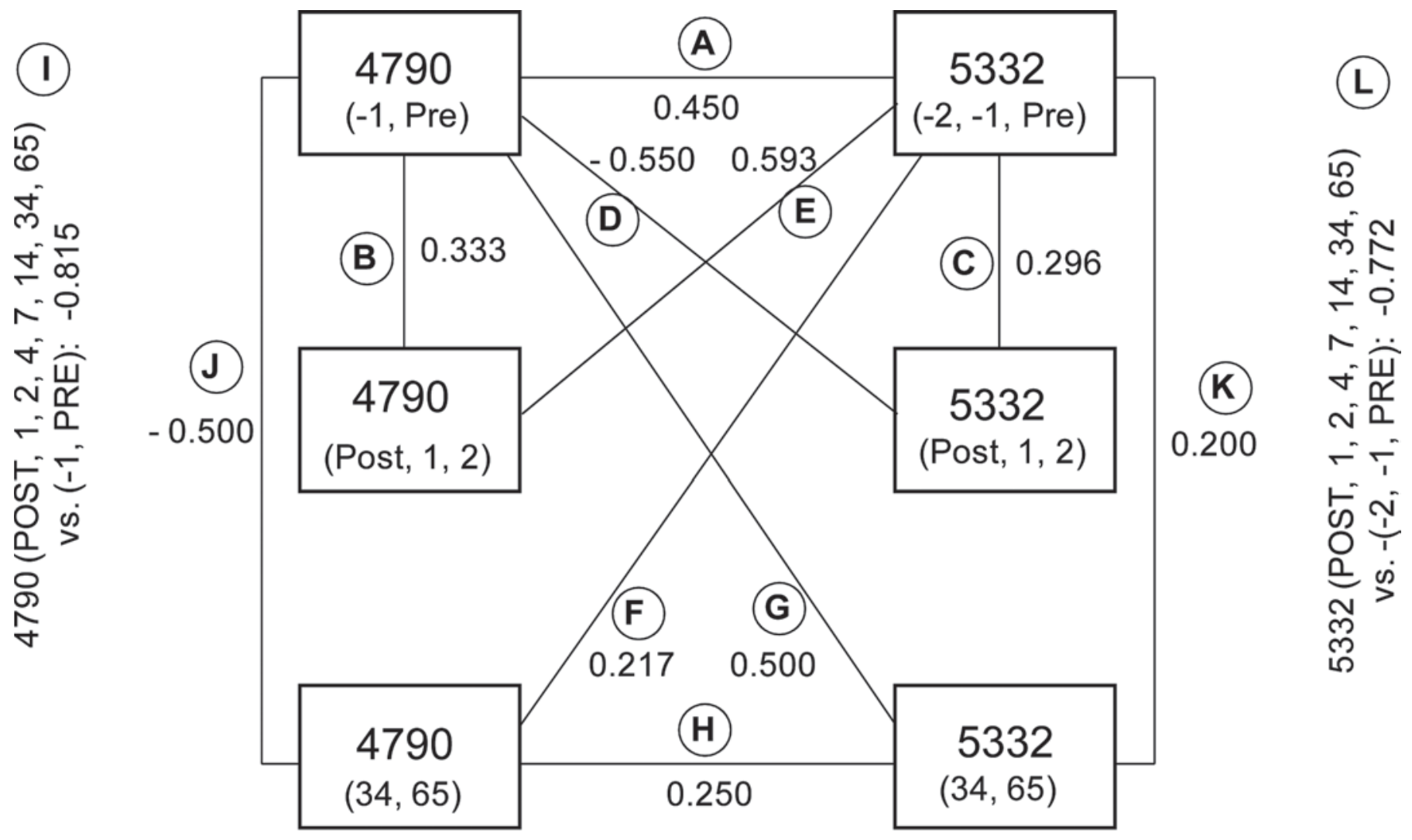

All 4790 vs. All 5332: 0.118

Figure 3. Analysis of similarity (ANOSIM) R-values for comparison of bacterial community composition (BCC) in liquid phase samples of ruminal contents in cows subjected to ruminal exchange (experiment 1). Boxes indicate cow and day of sampling relative to ruminal contents exchange, with "Pre" and "Post" indicating samples collected immediately before and immediately after exchange, respectively. R-values are placed along lines connecting groups of samples; $\mathrm{R}$ can potentially range from -1 (maximally similar) to +1 (maximally distinct). For example, the BCC for the later samples (d 34 and 65) for cow 4790 was much more similar to that of cow 4790 before the exchange (comparison J, low $\mathrm{R}$-value of -0.500) than to that of the BCC of the donor inoculum from cow 5332 before the exchange (comparison $\mathrm{F}$, much higher R-value of $+0.217)$. All positive R-values had $P$-values $<0.024$, and all negative R-values had $P$-values $>0.936$. Circled letters indicate comparisons between sample groups, discussed in text.

gests a degree of difference comparable to those before the exchange (comparison A).

To examine the extent to which specific community members responded to the exchange, specific AL were scored for their presence or absence before, or on the last 2 analysis days (d 34 and 65) after, the exchange. For this analysis, individual AL were included only if they were present in all preexchange samples or in both the 34 and $65 \mathrm{~d}$ samples. As shown in Table 1, $34 \mathrm{AL}$ $(33.1 \%)$ were shared by the cows in all of these samples before the exchange, and $31 \mathrm{AL}(28.0 \%)$ were shared in both cows at 34 and $65 \mathrm{~d}$ after the exchange. The number of AL unique to cow 4790 decreased dramatically (from 52 to 23 ) following the exchange, while the number of unique AL increased slightly (from 17 to 21 ) in cow 5332.
To compare persistence of individual AL following the exchange, the $115 \mathrm{AL}$ detected in all preexchange samples from an individual cow were examined for their presence in 34- and 65-d postexchange samples in both cows. Eighteen AL present only in the donor cow persisted in the donor cow following the exchange, but were not present (i.e., did not establish themselves at detectable levels) in the recipient cow. By contrast, 17 other AL originally present only in the donor cow before the exchange were detected in both the donor and recipient cows. Thus, these 17 AL both withstood the challenge of the non-native community inoculation, and successfully challenged the native community upon transfer to the rumen the other cow. Across the pair of cows, 56 of the $\mathrm{AL}$ present in the recipient cows before the exchange were not detected in the same cow 
Table 1. Amplicon lengths from automated ribosomal intergenic spacer analysis that were shared or not shared between cows before and after near-total exchange of ruminal contents

\begin{tabular}{|c|c|c|c|}
\hline \multirow[b]{2}{*}{ Item } & \multirow[b]{2}{*}{ Phase } & \multicolumn{2}{|c|}{ Number of amplicon lengths ${ }^{1}$} \\
\hline & & Preexchange $^{2}$ & Postexchange $^{3}$ \\
\hline \multicolumn{4}{|l|}{ Experiment 1} \\
\hline Cow 4790 only & Liquid & 52 & 23 \\
\hline Cow 5332 only & Liquid & 17 & 31 \\
\hline Both cows & Liquid & 34 & 21 \\
\hline \multicolumn{4}{|l|}{ Experiment 2} \\
\hline Cow 2897 only & Liquid & 24 & 22 \\
\hline Cow 3228 only & Liquid & 35 & 43 \\
\hline Both cows & Liquid & 19 & 76 \\
\hline Cow 2897 only & Solid & 40 & 37 \\
\hline Cow 3228 only & Solid & 8 & 12 \\
\hline Both cows & Solid & 2 & 24 \\
\hline
\end{tabular}

at both 34 and $65 \mathrm{~d}$ after the exchange. Most of these AL were represented by small peaks in the capillary electropherograms that were near the fluorescence detection limit.

Experiment 2. Exchange of ruminal contents (cf. PRE vs. POST in Figure 4) resulted in a temporary similarity in $\mathrm{pH}$ values between cows 2897 and 3228, but the differences were quickly reestablished, by end of the first day, after the exchange. In experiment 2 , as shown in Figure 5, cows differed significantly $(P<0.05)$ in prefeed $\mathrm{pH}$ prior to exchange of ruminal contents (cow 2897, pH 6.69; cow 3228, pH 6.20). The mean prefeed $\mathrm{pH}$ value for all time points after the switch for cow 2897 was 6.68 , remarkably similar to the mean value measured before the switch. By contrast, cow 3228 attained a mean prefeed $\mathrm{pH}$ of 6.52 , almost 0.3 units higher than its mean value before the exchange. Mean prefeed $\mathrm{pH}$ values for $\mathrm{d} 1,2$, and 4 following the switch for cows 2897 and 3228 were 6.58 and 6.47 respectively, similar to those of the postfeed means for all data points.

Changes in prefeed total VFA content in some respects mirrored those of prefeed pH. For cow 2897, whose prefeed ruminal $\mathrm{pH}$ returned to preexchange levels within $1 \mathrm{~d}$ of the exchange, the mean total VFA concentrations for $\mathrm{d} 1$ to 4 , and for all time points after the exchange (105.1 and $100.0 \mathrm{mM}$ ) were similar to the preexchange mean of $100.6 \mathrm{mM}$. For cow 3228, whose ruminal $\mathrm{pH}$ remained somewhat elevated above the preexchange range for weeks after the exchange, the postexchange mean total VFA concentrations for $\mathrm{d} 1$ to 4 and for all time points were 119.7 and $116.5 \mathrm{mM}$, respectively, somewhat lower than the preexchange mean, $(136.5 \mathrm{mM})$.
In experiment 2, the $\mathrm{BCC}$ of both the liquid and solid phases were analyzed, and generally displayed similar patterns. The ordination biplots of the liquid samples (Figure 5) revealed substantial changes over the course of the $62 \mathrm{~d}$ after exchange. Both cows generally appeared to achieve a $\mathrm{BCC}$ more similar to that of the preexchange $\mathrm{BCC}$ in the same cow than the preexchange $\mathrm{BCC}$ in the donor cow. However, neither cow displayed as clear a return to the original $\mathrm{BCC}$ as was observed in experiment 1 . The incomplete reconstitution of the BCC was verified by ANOSIM comparisons (Figure 6 ). As in the case of experiment 1 , the 2 cows displayed differences before exchange of ruminal contents (comparison $\mathrm{A}$ ) and at the late time points following the exchange (61 and $62 \mathrm{~d}$, comparison $\mathrm{H}$ ). For each cow, BCC differed from the original $\mathrm{BCC}$ over the few days following the exchange (comparisons $\mathrm{B}$ and $\mathrm{C}$ ), as expected for the exchange procedure. Comparison of $\mathrm{BCC}$ for the complete set of data points from the cow before the exchange with those in the same cow after the exchange yielded highly negative $\mathrm{R}$-values for both cows (comparisons I and L), suggesting that the BCC for each cow was similar before and after the exchange. However, for both cows, the positive R-values (comparisons $\mathrm{J}$ and $\mathrm{K}$ ) indicate substantial differences between the preexchange $\mathrm{BCC}$ and the later time points for the postexchange $\mathrm{BCC}$ in the same cow, and the R-values from comparison of $\mathrm{BCC}$ at the later time points for each recipient cow with the preexchange $\mathrm{BCC}$ from both donor and recipient cow were relatively similar (comparisons $\mathrm{F}$ and $\mathrm{J}$ for cow 2897, comparisons $\mathrm{G}$ and $\mathrm{K}$ for cow 3228). These data suggest that even by d 61 and 62 , the cows had not reconstituted their original bacterial community composition. 
a)

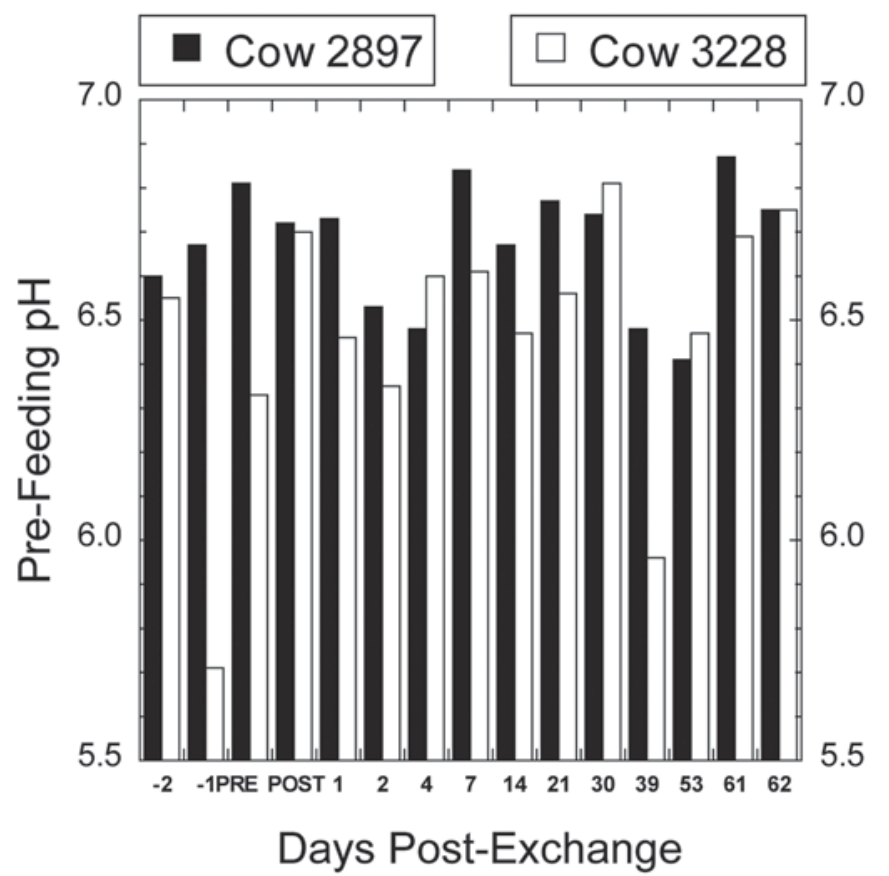

b)

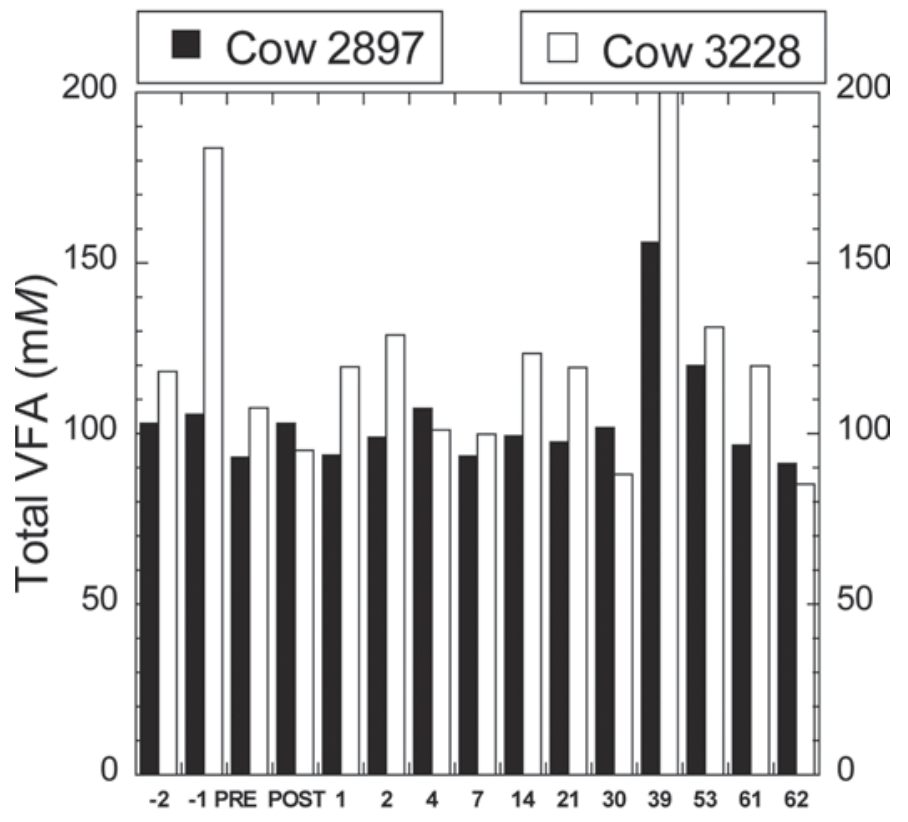

Figure 4. Prefeed $\mathrm{pH}$ and prefeed total VFA concentrations in the rumina of 2 cows in experiment 2 . PRE $=$ sample collected immediately before exchange. POST $=$ sample immediately after exchange. All other samples were collected immediately before feeding on the indicated number of days before the exchange (negative value) or after the exchange (positive value). Samples were collected as individual but analyzed in duplicate.
As shown in Table 1, 19 AL (25.0\%) were shared by the cows in all of the liquid-phase samples before the exchange, and $76 \mathrm{AL}(53.9 \%)$ were shared in both cows at 61 and $62 \mathrm{~d}$ after the exchange. By contrast, $2(4.0 \%)$ and $24(32.9 \%)$ of the solid-phase AL were shared in both cows at 61 and $62 \mathrm{~d}$ after the exchange, respectively. To compare persistence of individual AL following the exchange, the $152 \mathrm{AL}$ in the liquid phase (and 93 in the solid phase) that were present in all preexchange samples from an individual cow were examined for their presence in both 61 - and $62-\mathrm{d}$ postexchange samples in both cows. Nine liquid-phase AL and 13 solid-phase AL detected in the donor cow before the exchange persisted in the donor, but were not present (i.e., did not establish themselves at detectable levels) in the recipient cow. By contrast, 30 other liquid-phase (and 12 solid-phase) AL originally present only in the donor cow before the exchange persisted in both the donor and recipient cows. Thus, these AL both withstood the challenge of the non-native community inoculation, and successfully challenged the native community upon transfer to the rumen of the other cow. Across the pair of cows, 13 of the liquid-phase AL (and 22 solid-phase $\mathrm{AL}$ ) present in the recipient cows before the exchange were not detected in the same cow at both 61 and $62 \mathrm{~d}$ after the exchange. As in the case of experiment 1 , these $\mathrm{AL}$ represented small peaks in the capillary electropherogram that were often near the fluorescence detection limit.

\section{DISCUSSION}

Previous studies employing wholesale cross-inoculation of ruminal contents across individual ruminants have focused on resulting changes in eating behavior, ruminal acidosis, and milk production and composition. Satter and Bringe (1969) showed that near-total exchange of ruminal contents between a Holstein cow fed a high-grain diet and one fed a high-forage diet resulted in changes of ruminal chemistry and milk composition that more closely represented those of the donor animal; but in these experiments, the diet composition was switched between the cows coincident with the exchange of ruminal contents. Cole (1991) showed that exchange of approximately $50 \%$ of ruminal contents between sheep had variable effects on DMI depending on whether the animals had been fasted before the exchange. Neither of these studies involved examination of the ruminal microflora before or after the exchange.

Among the major microbial groups of the rumen (bacteria, archaea, protists, and fungi), the bacteria are 

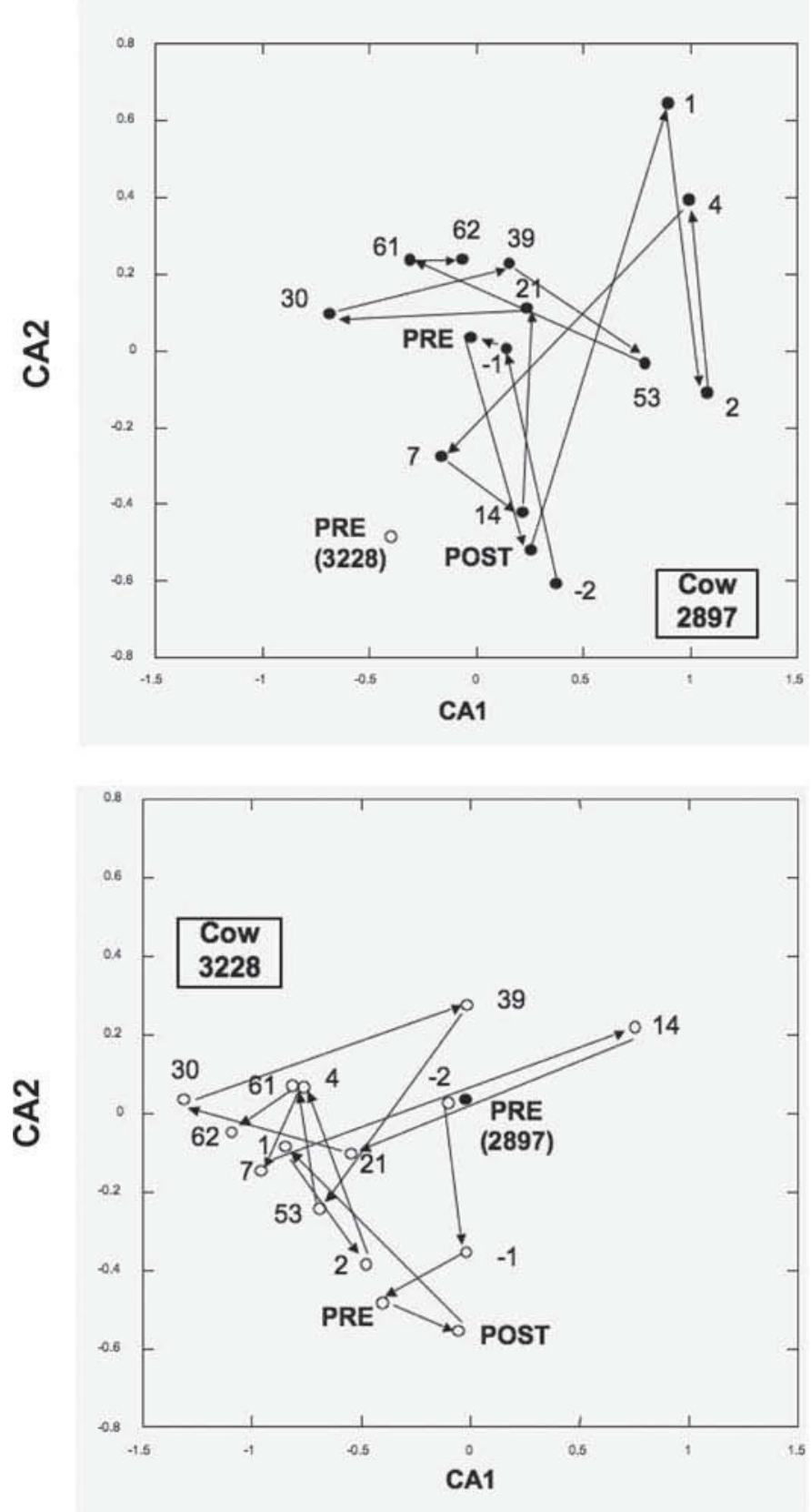

Figure 5. Ordination biplots of bacterial community composition (BCC) for experiment 2. Coordinates were obtained from correspondence analysis of capillary electrophoregrams resulting from automated ribosomal intergenic spacer analysis of amplified internal transcribed spacer segments of microbial DNA, using domain bacteriaspecific primers (see text). CA1 and CA2 represent the first and second correspondence axes, respectively. Each data point represents a single sample at the indicated time (in days) relative to the day of the ruminal contents exchange. PRE $=$ sample collected immediately before exchange. POST $=$ sample immediately after exchange. Samples having similar BCC are located more closely together, and distance between points increases as BCC becomes less similar. generally regarded as the most taxonomically diverse and the most responsible for fermentation of feedstuffs to the VFA used by the cow as an energy source (Russell, 2002). The known species of bacteria in the rumen constitute only a small fraction of ruminal bacteria (Krause and Russell, 1996; Stevenson and Weimer, 2007). Previous ARISA studies have revealed that the ruminal BCC differs even between cows fed the same diet (Weimer et al., 2010; Welkie et al., 2010), in a manner that suggests that individual cows may harbor a bacterial community particularly well adapted to the individual host animal. Likewise, Tatsuoka et al., (2007) demonstrated by PCR single-strand conformation polymorphism that the composition of the methanogenic archaeal community in the bovine rumen appears to be relatively specific to individual cows.

The potentially specific relationship between the cow and her ruminal bacterial community led us to examine the $\mathrm{BCC}$ within individual cows in response to a massive challenge from a bacterial community well adapted to another cow maintained on the same diet. Specifically, we intentionally depleted the microbial population in one cow by removing of most (>95\%) of its ruminal contents and replaced those ruminal contents with those of another cow on the same diet. Simultaneously, we replaced the ruminal contents from the second cow with that of the first cow, to achieve an almost complete exchange of ruminal contents. We then examined the response of the bacterial community in each cow, using a combination of ARISA (e.g., see Fisher and Triplett, 1999; Brown et al., 2005; Shade et al., 2008]) and correspondence analysis (a multivariate statistical method that analyzes data based on the relative abundance of individual analytical units, viz., $\mathrm{AL}$ produced by PCR of the internally transcribed region between ribosomal RNA genes). The combination of these methods has recently been used to follow changes in ruminal $\mathrm{BCC}$ within individual cows during the feeding cycle (Welkie et al., 2010) and in response to dietary changes (Weimer et al., 2010).

In the first experiment, exchange of ruminal contents was followed by a reassortment of the bacterial community in each cow to yield a BCC that ultimately was very similar (as determined by correspondence analysis and ANOSIM) to the BCC before the exchange. This return to the original $\mathrm{BCC}$ was substantial within 2 wk, and was essentially complete by 9 wk. Examination of individual AL revealed that some AL from the donor cows persisted in the recipient cows following the ruminal exchange, whereas a generally smaller number of AL originally present in the recipient were lost upon challenge with the donor cow inoculum. 


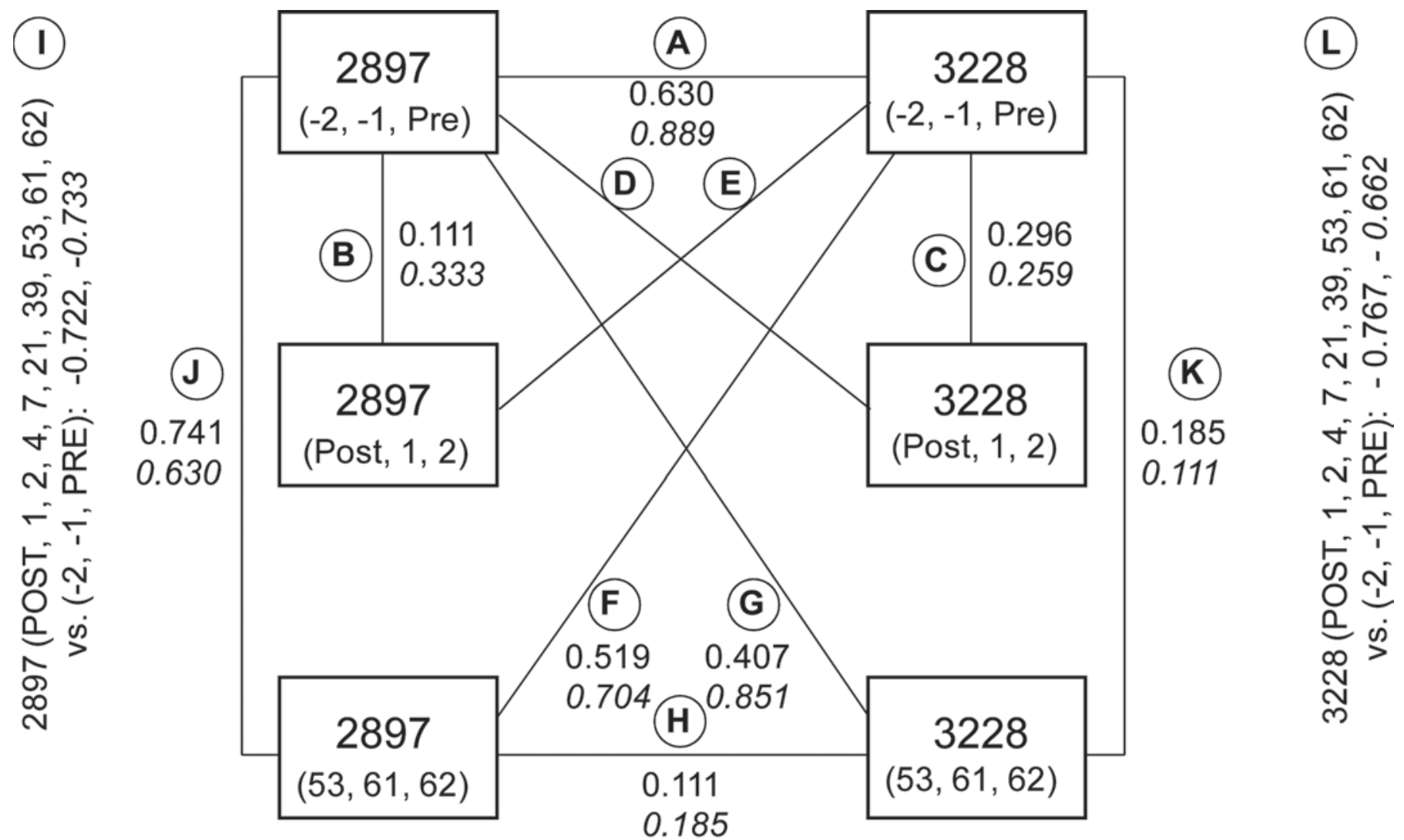

(M) All 2897 vs. All 3228: $0.158,0.459$

Figure 6. Comparison of amplicon profiles using analysis of similarity (ANOSIM) R-values for comparison of bacterial community composition (BCC) in liquid and solid phase samples of ruminal contents in cows subjected to ruminal exchange (experiment 2). Boxes indicate cow and day of sampling relative to ruminal contents exchange, with "Pre" and "Post" indicating samples collected immediately before and immediately after exchange, respectively. R-values (plain font for liquid phase, italic for solid phase) are placed along lines connecting groups of samples; $\mathrm{R}$-values can potentially range from -1 (maximally similar) to +1 (maximally distinct). All positive R-values had $P$-values $\leq 0.040$, and all negative R-values had $P$-values $>0.992$. Circled letters indicate comparisons between sample groups, as discussed in text.

In the second experiment employing 2 different cows, correspondence analysis and ANOSIM indicated that 1 cow had essentially reconstituted her BCC within approximately $3 \mathrm{wk}$, and by d 62 , had a BCC almost identical to that before the exchange. For the second cow in experiment 2 , a return to the original $\mathrm{BCC}$ was not achieved by the end of the experiment $(62 \mathrm{~d})$, although the $\mathrm{BCC}$ by $\mathrm{d} 62$ was more similar to the original $\mathrm{BCC}$ than to that of the original donor cow (Figures 5 and 6). As in experiment 1, some AL from the donor cow persisted in the recipient cow, and others originally present in the recipient that were lost from the recipient upon the inoculum challenge. The $\mathrm{AL}$ that were displaced from the recipient were generally of minor abundance in the community, and at least some of the apparent loss of AL may have been due to an inability to detect these taxa at very low levels in the bulk population. Whereas postexchange differences in BCC were found for all cows, their bacterial communities generally resembled the preexchange community more than the community of the donor cow. Thus, the bacterial communities displayed substantial resilience, a hallmark of ecological communities generally displaying high species diversity and stability (Allison and Martiny, 2008).

For both exchange experiments, the cows in each pair differed substantially in prefeed ruminal $\mathrm{pH}$ (by $\sim 0.6$ units) and in prefeed ruminal total VFA (by 20-40 $\mathrm{m} M$ ), permitting a comparison of response of these parameters to the exchange of ruminal contents. For both cows in experiment 1, and 1 of the cows in experiment 2 , both prefeed $\mathrm{pH}$ and prefeed total VFA returned to their original value within $1 \mathrm{~d}$ of sampling. For the other cow in experiment 2, $\mathrm{pH}$ and total VFA remained 
slightly elevated after the exchange. This cow also had a $\mathrm{BCC}$ at the end of the 9-wk experiment that least resembled the $\mathrm{BCC}$ at the time before the exchange.

The rapid recovery in prefeed $\mathrm{pH}$ (by the first day after the exchange) was not unexpected, given the major role the cow has in regulating $\mathrm{pH}$ via rumination, salivation, and VFA absorption. The rapid recovery of prefeed ruminal total VFA, which also occurred within the first day of the exchange, was more surprising, given that the ruminal $\mathrm{BCC}$, the primary source of VFA production, displayed a more gradual change over time. This observation suggests that individual cows exert considerable control on their ruminal VFA content, possibly by regulating the rate and extent of VFA absorption. These results are in accord with recent work with sheep showing that individual animals differ substantially in the activity of transport proteins involved in uptake of ions and VFA across the ruminal epithelia (Penner et al., 2009).

In each of the 2 experiments, substantial preexchange differences were found between the cows with respect to both ruminal chemistry ( $\mathrm{pH}$, total VFA) and BCC. Because the differences in ruminal chemistry were rapidly reestablished after the exchange, one would expect that the members of the bacterial community of the recipient cow would be favored by rapid return of the more familiar environmental conditions. Indeed, the rumen that did not return to its preexchange $\mathrm{pH}$ and total VFA content (from cow 3228) also displayed the greatest difference in $\mathrm{BCC}$ in the preexchange vs. late postexchange samples. It appears that ruminal chemistry may both affect, and be affected by, BCC. It would be of interest to perform similar ruminal exchange experiments on pairs of cows that had similar ruminal chemistries but demonstrable differences in BCC.

The data obtained here have implications for attempts to modify the ruminal fermentation by targeted addition of microbes into the ruminant or into ruminant rations. Previous successes in establishing introduced bacteria into the rumen have involved species with unique metabolic capabilities that can fill empty habitat niches (e.g., mimosine degradation by Synergistes jonesii, Jones and Megarrity, 1986; or fluoroacetate degradation by a recombinant Butyrivibrio strain containing a dehalogenase gene, Gregg et al., 1998). Introductions of bacteria that must compete with indigenous microflora have proven less successful. For example, Varel et al. (1995) showed that neither a ruminal strain of Clostridium longisporum ATCC 49440 nor a pig intestinal isolate of $C$. herbivorans ATCC 54408 , both actively cellulolytic bacteria, persisted in the bovine rumen for $72 \mathrm{~h}$ despite their massive inoculations into almost-emptied rumina. Establishment of other cellulolytic strains has been demonstrated, at least transiently, but requires some combination of repeated dosing, immature recipient animal with undeveloped ruminal bacterial communities, accessory probiotic strains, or other forms of selective pressure (Krause et al., 1999; Chiquette et al., 2007; Paul et al., 2007). Our data suggest that the resistance of the indigenous microflora to colonization by foreign bacterial strains extends even to those strains well adapted to other cows fed the same diet as the recipient animal. The apparent host specificity of the ruminal bacterial community reaffirms the ecological principles of inertia (the internal resistance of established complex biological communities to change), and resilience (the ability to recover following disturbance; Westman, 1978). As in other microbial habitats, introduced species must surmount substantial ecological barriers to displace indigenous strains well adapted to the particular ruminal habitat in which they reside.

\section{ACKNOWLEDGMENTS}

We thank the barn crews at the US Dairy Forage Research Center Farm (Prairie du Sac, WI) and at the Dairy Cattle Instructional Center at the University of Wisconsin-Madison for animal feeding and handling. We also thank Christine Odt, US Dairy Forage Research Center, for technical assistance. H. C. Mantovani received a sabbatical fellowship from CAPES (Brasilia, Brazil).

\section{REFERENCES}

Allison, S. D., and J. B. H. Martiny. 2008. Resistance, resilience, and redundancy in microbial communities. Proc. Natl. Acad. Sci. USA 105:11512-11519.

Brown, M. V., M. Schwalbach, I. Hewson, and J. Furhman. 2005. Coupling of 16S-ITS-rDNA clone libraries and automated ribosomal interspecies spacer analysis to show marine microbial diversity: Development and application of a time series. Environ. Microbiol. 7:1466-1479.

Chiquette, J., G. Talbot, F. Markwell, N. Nili, and R. J. Forster. 2007. Repeated ruminal dosing of Ruminococcus flavefaciens NJ along with a probiotic mixture in forage or concentrate-fed dairy cows: Effect on ruminal fermentation, cellulolytic populations and in sacco digestibility. Can. J. Anim. Sci. 87:237-249.

Clarke, K. R. 1993. Non-parmetric multivariate analysis of changes in community structure. Aust. J. Ecol. 17:117-143.

Cole, N. A. 1991. Effects of animal-to-animal exchange of ruminal contents on the feed intake and ruminal characteristics of fed and fasted lambs. J. Anim. Sci. 69:1795-1803.

Fisher, M. M., and E. W. Triplett. 1999. Automated approach for ribosomal intergenic spacer analysis of microbial diversity and its application to freshwater environments. Appl. Environ. Microbiol. 63:4630-4636.

Gregg, K., B. Hamdorf, K. Henderson, J. Kopecny, and C. Wong. 1998. Genetically modified ruminal bacteria protect sheep from fluoroacetate poisoning. Appl. Environ. Microbiol. 64:3496-3498.

Hungate, R. E. 1966. The Rumen and Its Microbes. Academic Press, New York, NY.

Jones, R. J., and R. G. Megarrity. 1986. Successful transfer of DHPdegrading bacteria from Hawaiian goats to Australian ruminants to overcome the toxicity of Leucaena. Aust. Vet. J. 63:259-262. 
Krause, D. O., and J. B. Russell. 1996. How many ruminal bacteria are there? J. Dairy Sci. 79:1467-1475.

Krause, D. O., W. J. M. Smith, F. M. E. Ryan, R. I. Mackie, and C. S. McSweeney. 1999. Use of 16S-RNA based techniques to investigate the succession of microbial populations in the immature lamb rumen: Tracking of a specific strain of inoculated Ruminococcus and interactions with other microbial populations in vivo. Microb. Ecol. 38:365-376.

Ludwig, J. A., and J. F. Reynolds. 1988. Community ordination. Pages 205-274 in Statistical Ecology. John Wiley and Sons, New York, NY.

Paul, S. S., D. N. Kamra, V. R. B. Sastry, and N. Agarwal. 2007. Effect of administration of an anaerobic gut fungus isolated from wild blue bull (Boselaphus tragocameulus) to buffaloes (Bubalus bubalis) on in vivo ruminal fermentation and digestion of nutrients. Anim. Feed Sci. Technol. 115:143-157.

Penner, G. B., J. R. Aschenbach, G. Gäbel, R. Rackwitz, and M. Oba. 2009. Epithelial capacity for apical uptake of short chain fatty acids is a key determinant of intraruminal $\mathrm{pH}$ and the susceptibility to subacute ruminal acidosis in sheep. J. Nutr. 139:1714-1720.

Russell, J. B. 2002. Rumen Microbiology and Its Role in Ruminant Nutrition. James B. Russell, Ithaca, NY.

Satter, L. D., and A. N. Bringe. 1969. The effect of abrupt ration changes on milk and blood components. J. Dairy Sci. 52:17761780.

Shade, A., S. E. Jones, and K. D. McMahon. 2008. The influence of habitat heterogeneity on bacterial community composition and dynamics. Environ. Microbiol. 10:1057-1067.
Stevenson, D. M., and P. J. Weimer. 2007. Dominance of Prevotella and low abundance of classical ruminal bacterial species in the bovine rumen revealed by relative quantification real-time PCR. Appl. Microbiol. Biotechnol. 75:165-174.

Tatsuoka, N., N. Mohammed, M. Mitsumori, K. Tajima, K. Hara, M. Kurihara, and H. Itabashi. 2007. Analysis of methanogens in the bovine rumen by polymerase chain reaction single-strand conformation polymorphism. Anim. Sci. J. 78:512-518.

Varel, V. H., J. T. Yen, and K. K. Kreikemeier. 1995. Addition of cellulolytic clostridia to the bovine rumen and pig intestinal tract. Appl. Environ. Microbiol. 61:1116-1119.

Weimer, P. J. 1998. Manipulating ruminal fermentation: A microbial ecological perspective. J. Anim. Sci. 76:3114-3122.

Weimer, P. J., Y. Shi, and C. L. Odt. 1991. A segmented gas/liquid delivery system for continuous culture of microorganisms on solid substrates, and its use for growth of Ruminococcus flavefaciens on cellulose. Appl. Microbiol. Biotechnol. 36:178-183.

Weimer, P. J. D. M. Stevenson, and D. R. Mertens. 2010. Shifts in bacterial community composition in the rumen of lactating dairy cows under conditions of milk fat depression. J. Dairy Sci 93:265-278.

Welkie, D. G., D. M. Stevenson, and P. J. Weimer. 2010. ARISA analysis of ruminal bacterial community dynamics in lactating dairy cows during the feeding cycle. Anaerobe 16:94-100.

Westman, W. E. 1978. Measuring the inertia and resilience of ecosystems. Bioscience 28:705-710. 